\title{
POLÍTICAS DE REGULAÇÃO, PESQUISA E PEDAGOGIA NA EDUCAÇÃO INFÂNTIL, PRIMEIRA ETAPA DA EDUCAÇÃO BÁSICA
}

\author{
Ana Lúcia Goulart de Faria*
}

\begin{abstract}
RESUMO: Como fazer um mapa durante um terremoto, este artigo refaz as trajetórias pelas quais passaram creche e pré-escola, até tornarem-se, pela LDB de 1996, instituições de educação infantil responsáveis pela primeira etapa da educação básica. Mostra também que as tentativas de articulação entre pesquisa, política e prática pedagógica garantiram avanço e inovação na área, que vem construindo a Pedagogia da Infância e se empenha em garantir, pela esfera municipal, o direito à educação das crianças de 0 a 6 anos. Enquanto área muito jovem da educação, acaba sofrendo pressões que podem levar a um retrocesso, como o que vem ocorrendo no momento no Brasil. Sem concluir, o texto permite constatar a transgressão instalada pela educação infantil que, ao dar vida a uma infância que continua nas séries iniciais, torna-se o grande impedimento para uma política nacional integrada para a infância.
\end{abstract}

Palavras-chave: Educação infantil. Políticas para a infância. Criança pequena. Creche. Pré-escola. Primeira etapa da educação básica.

REGULATION POLICIES, RESEARCH AND PEDAGOGY IN CHILD EDUCATION, FIRST STEP OF THE BASIC EDUCATION

ABSTRACT: This paper describes the trajectory of kindergarten and pre-school until the 1966 Brazilian Education Basic Tenets Law (LDB) transformed them into the child education institution responsible for the first phase of basic education. It shows that the attempts to articulate research, policies and pedagogical practices ensured progress and innovation in this area, which have been building a

Professora da Faculdade de Educação da Universidade Estadual de Campinas (UNICAMP). E-mail: cripeq@unicamp.br

Educ. Soc., Campinas, vol. 26, n. 92, p. 1013-1038, Especial - Out. 2005 
Políticas de regulação, pesquisa e pedagogia na educação infantil...

child pedagogy involved in guaranteeing, at the municipal level, the right to education of the 0-6 year olds. Still a new area in education, it suffers pressures that may lead to a retroversion, as is the case nowadays. Eluding conclusions, this text highlights that the transgression implemented by a child education giving life to a childhood that extends to the first grades practically hinders nationally integrated policies. This is also the case in Italy, where 0-3 year olds education in kindergarten is not free and where a government fell, in 1968, when people wanted free pre-school.

Key words: Child education. Integrated policies for childhood. Little children. Kindergarten. Pre-school. First phase of basic education.

em sido produto da grande transformação nos conceitos de infância e criança a reformulação de políticas públicas que as contemplem na área da educação. Transformação esta que ainda não atingiu todo o espectro de possibilidades nas áreas da assistência e saúde, na jurídica e na religiosa. Podemos dizer que essa transformação vem sendo construída no Brasil desde 1946, com a investigação de Florestan Fernandes (1979), que deu voz aos que hoje chamamos de "novos atores" na cena social, mas que, com certeza, não são tão novos assim: as crianças, os negros, os índios, as mulheres. Somadas às pesquisas que começaram a ser realizadas 30 anos depois, produto do movimento feminista, totalmente inovadoras ao investigarem a produção das culturas infantis entre as crianças pequenas nos espaços públicos coletivos de educação institucionalizada, temos as bases teóricas e científicas que nos orientam hoje ao entender as necessidades e os desejos das crianças. Ao vê-las como sujeitos de direito, superamos a identidade única que lhes foi atribuída e que afirma sua incompletude com relação ao adulto, tomando-as como apenas um vir-a-ser. Desde aí, devese considerar uma infância que, como toda fase da vida, é provisória, construída, e fica incorporada nas próximas fases. Nesse movimento, todos somos "um vir-a-ser" e também o que somos hoje e o que fomos ontem, concomitantemente. Dito pelo escritor-poeta Saramago (apud Carvalhal, 1997, p. 50), quando se refere a sua autobiografia: “(...) o menino que nós fomos está contido em nós, mas o adulto que nós somos não está contido nesse menino. Esse menino é uma coisa em si (...) para uma criança o mundo é todo ele uma tentação (...) deixa-te levar pela criança que foste". 
As crianças começaram a estar no centro das preocupações da pedagogia já com a Escola Nova, tão criticada ainda hoje como escola burguesa, espontaneísta, sem conteúdo. Foi a partir daí que vimos os pioneiros da Escola Nova, que traduziram para o português Durkheim e as primeiras obras da psicologia, incluírem a creche e a pré-escola, geralmente esquecidas, na história de uma educação que havia privilegiado a escolarização obrigatória como direito das camadas populares. Os estudos ditos culturais, que também hoje colocam a temática da infância, favoreceram os estudos sobre a criança concreta, já iniciados com o materialismo histórico-dialético: criança capaz de estabelecer múltiplas relações, pertencente a uma determinada classe/camada social, menino, menina, negra, branca, indígena, mas sempre criatura e criadora da história e da cultura em condiçôes dadas, que sofre o que a italiana Bertoni Jovine (1965) chama da "dupla alienação da infância", ao ser explorada, nas camadas populares, e privatizada nas camadas médias e altas. O furto do lúdico (Marcellino, 1990) alcança as mais diferentes infâncias. O homem faz a história em condiçôes dadas já disse Marx, questionado por algumas feministas dos anos 70 do século passado, quando faziam referência às tais condições dadas com as mulheres ausentes. Polemizo com elas, agregando as crianças (entre outros ausentes) e também observando nas tais condiçôes dadas as formas de resistência, de silêncio e de submissão.

Porém, não foram as crianças nessa fase da vida que reclamaram seus direitos. Foram adultos lúcidos que lutaram por eles, conquistando assim a possibilidade do coletivo infantil, isto é, de a criança ser educada na esfera pública complementar à esfera privada da família, por profissionais diplomados distintos dos parentes, para a construção da sua cidadania; e de conviver com a diversidade cultural brasileira, produzindo as culturas infantis, entre elas e entre elas com os adultos.

As feministas, tendo lutado pelos direitos de a mulher trabalhar, estudar, namorar e ser mãe, lutaram também, no Brasil dos anos de 1970, pelo direito de seus/suas filhos/as à creche - o que garantiria que os outros direitos femininos fossem garantidos. Agregaram a esta mesma luta, nos anos de 1980, o direito das crianças à educação anterior à escola obrigatória. Assim, agora sujeitos de direitos, as crianças pequenas também serão legisladas.

O binômio atenção/controle pode favorecer um tipo de análise das políticas de regulação da educação básica aqui na sua primeira etapa, na educação infantil: cada vez que é dada atenção e um novo ator social en- 
Políticas de regulação, pesquisa e pedagogia na educação infantil...

tra em cena, um controle o regerá. No nosso país será no finalzinho do século XXI que as crianças de 0 a 6 anos passarão para o reino da cidadania.

Hoje as categorias de gênero e idade passam a dar visibilidade aos novos atores e, assim, a temática da infância - tanto quanto a dos velhos, jovens, mulheres, gays etc. - é enfatizada pelas teorias ditas pós-modernas. Esta atenção que é dada às crianças pequenas de 0 a 6 anos, assim como a todos os novos atores, vem acompanhada do respectivo controle:

No Brasil, o atual processo de escolarização das crianças pequenas de 4 a 6 anos, ao mesmo tempo em que anuncia a decidida inserção da criança na cultura, o reconhecimento de sua cidadania como um sujeito de direitos, pode vir a ser uma maneira de captura e de escolarização precoce no sentido da disciplinarização, normalização do corpo, das palavras e gestos, na produção de um determinado tipo de aprendiz trazendo, portanto, uma rejeição à alteridade e às diferenças que as crianças anunciam, enquanto tais. (Abramowicz, 2003, p. 16)

\section{A trajetória da pesquisa}

Embora ainda hoje tenhamos nas creches alguns resquícios da enfermagem, no trato com os bebês (por exemplo, o emprego de palavras e práticas hospitalares tais como: solário, lactário, berçário, peso e medida etc.), e tenhamos fortemente a escola na educação das crianças maiores (nas filas, divisão por idade, lápis e papel, mesa e cadeira etc.), o que deve ser destacado no movimento histórico aqui enfocado é a construção de uma pedagogia da educação infantil fundamentalmente não-escolarizante, que incorpora as pesquisas de várias áreas do conhecimento e busca conhecer a criança em ambiente coletivo, na produção das culturas infantis.

Foi necessário que essa abordagem das ciências sociais acompanhasse inúmeras pesquisas, até que pudéssemos falar numa "pedagogia da infância”. Desde os anos de 1970, na França e na Itália, têm sido feitas investigaçōes em que, olhando, observando, dando voz e ouvidos à criança - mesmo quando ela ainda não fala, anda ou escreve -, torna-se possível reconhecê-la como capaz de estabelecer múltiplas relações, com um alto e sofisticado grau de comunicação com crianças de mesma ou de idade diferente e com adultos. No Brasil, esse tipo de pesquisa não começa- 
ria muito depois: a professora Clotilde Rosseti-Ferreira, no final da década de 1970 e início dos anos de 1980, estava atenta às pioneiras pesquisas francesas e italianas, que investigavam as crianças em creches. Por exemplo, constam da bibliografia do trabalho publicado sobre a interação criança-criança (Carvalho \& Beraldo, 1989), pelo grupo da USP, as italianas Tullia Musatti, Susanna Mantovani, Laura Camaione e a perspectiva da criança construtora de cultura. ${ }^{1}$ Tendo como referência Camaione, a produção das culturas infantis no Brasil é investigada pela psicologia como o "ressurgimento" de uma área de pesquisa que enfoca a interação criança-criança.

Já em 1976, falando do adultocentrismo no simpósio "Educação como forma de colonialismo", realizado na 28a reunião da SBPC, Fulvia Rosemberg questionou se "a psicologia estaria apta a fornecer alternativas, pelo menos ao nível do conhecimento, a estes impasses da educação de crianças?" (p. 1.468) e complementou na nota 1: "analisar a psicologia nesta perspectiva significa adotar a postura da sociologia do conhecimento. No campo da psicologia do desenvolvimento, a reflexão sociológica é incipiente (...)".

A partir deste questionamento, a Fundação Carlos Chagas (FCC) inovaria nas pesquisas educacionais, investigando a mulher e o feminismo e, em seguida, iniciando a pesquisa sobre as crianças de 0 a 6 anos, principalmente referidas nas políticas públicas. Essa posição de vanguarda levou essa instituição de pesquisa a um protagonismo na formulação dos conteúdos das políticas para essa fase da vida: na nova Constituição de 1988, no interior da LDB de 1996 e na criação da Coordenadoria de Educação Infantil (COEDI) do MEC, em 1992.

Na SBPC de 1995, em São Luiz, as mesmas pesquisadoras da FCC, feministas e "criancistas", Fúlvia Rosemberg e Maria Malta Campos apresentam o documento azul "das carinhas", ${ }^{2}$ encomendado pela COEDI-MEC: "Critérios de atendimento de uma creche que respeita os direitos fundamentais da criança", e o vídeo "Esta creche respeita criança”, hoje ainda referências para a definição da política nacional do Governo Lula, incorporados em seus "Parâmetros de qualidade para a educação infantil" (2005).

Pode-se notar neste movimento uma crescente articulação entre pesquisa, política e pedagogia na educação infantil, tanto oscilando a ênfase entre a atenção e o controle como na concomitância e contradição 
Políticas de regulação, pesquisa e pedagogia na educação infantil...

do binômio. Mesmo sem uma amplitude nacional, cada iniciativa, ainda que isolada, na política, na pedagogia ou na pesquisa, tem quase sempre pretendido relacionar esses três segmentos. ${ }^{3}$

Mas os estudos e as pesquisas sobre a escola por bastante tempo negligenciaram a educação das crianças pequenas. $\mathrm{O}$ primeiro estado da arte realizado na área da educação infantil foi feito por Eloísa Rocha (1999a), no seu doutorado sobre os trabalhos apresentados em congressos científicos na década de 1990. E ficou demonstrado que uma nova geração de doutores/as pesquisadores/as vem estudando e desafiando a pedagogia escolar como única referência para uma pedagogia da infância que contemple a especificidade da pequena infância, trazendo outras categorias de análise para a pesquisa da educação das crianças pequenas: tempo, espaço, relações, gênero, classes sociais, arranjos familiares, transgressão, culturas infantis, brincar, documentação, identidades, planejamento por projeto, performance, diferente, outro, linguagens, movimento, gesto, criança, alteridade, turma, instalação, não-avaliação, observação, cuidado. Isso, em vez dos convencionais: deficiência, indisciplina, hiperativo, carente, família desestruturada, anamnese, rotina, assistência, aula, didática, classe, aluno, ensino, currículo, vir-a-ser, sala de aula, desenvolvimento.

Para comemorar o Ano Internacional da Criança na Itália, dois volumes foram organizados por La Guardia \& Lucchini (1980). Entre as pesquisas publicadas, a professora Susanna Mantovani, junto com Rita Gay, escreve Educadora de creche: uma profissão a ser inventada, rompendo com o binarismo creche assistencial/educacional. A "assistência científica" estudada por Kulhmann Jr. (1991) invalida a noção de que a assistência não educa. No entanto, além dela e da escola, existem outras instituições educativas, como, por exemplo, os parques infantis paulistanos em 1935, que pude analisar como uma experiência educacional embora não-escolar (Faria, 2002).

Sonia Kramer em 1982 inaugura nossas publicações sobre a educação das crianças de 0 a 6 anos, pesquisa os antecedentes brasileiros para uma educação da criança pequena, história esta estudada em São Paulo por Tizuko Kishimoto (1988), que, depois, revisitando Froebel, aproxima-se da antropologia para estudar o brincar como manifestação cultural da pequena infância (Kishimoto, 1992).

Como se vê, estamos nesse movimento diante de uma nova profissão, de uma nova instituição educativa, que prevê para sua análise e críti- 
ca um olhar diferente daquele voltado tradicionalmente para a escola. O compromisso da pesquisa com esta pequena infância que não fala, não anda, não escreve, não lê se distingue inclusive no instrumental que a sociedade contemporânea coloca à sua disposição: a gravação em vídeo, por exemplo, que permite que se conheçam de fato as "narrativas" infantis desde os bebês. A necessidade de ética e a responsabilidade da pesquisa com crianças pequenas são alertadas por Becchi (1983), que a denomina de pesquisa superinterpretativa: a criança não negociará conosco, não será nossa interlocutora para discutir o processo e os resultados. ${ }^{4}$ Além do mais, com a pesquisa, a formação das profissionais foi levando as inovaçôes às redes públicas municipais, que se constituiriam em campos de referência indutores de políticas públicas.

Desde então, a pesquisa na área da educação infantil vem aumentando e se sofisticando. Divulgada em congressos acadêmicos e, cada vez mais, ampliando seu campo para além dos grupos sobre a pequena infância, como, por exemplo, os grupos de História da Educação e da Sociologia da Educação da ANPED. Várias revistas acadêmicas têm trazido com regularidade artigos e/ou fazem números temáticos sobre a infância. ${ }^{5}$ Em 2003, a revista não-acadêmica Pátio, da editora Artes Médicas, lança a Pátio-educação infantil, também revista não-acadêmica, porém com conselho editorial predominantemente acadêmico e fazendo divulgação das pesquisas da área. Temos muitos temas tratados e outros pouco trabalhados, embora sendo vieses relevantes, como é o caso dos estudos sobre a família. A sociologia da família de alguma forma é nossa aliada, mesmo não colocando a criança no centro de sua investigação: a criança é filho e filha, não protagonista, como em nosso enfoque. Do mesmo modo as pesquisas médicas de caráter preventivo, as quais, mesmo tratando da área da pediatria, elegem como centro das investigaçôes o adulto e a doença, ainda quando se estuda a primeira fase da vida.

Mobilizando áreas ou segmentos que pesquisam a infância e seus tempos e espaços de vida, como a história, a psicologia, a sociologia, a antropologia, a pedagogia, a demografia, a arquitetura, estamos agora rumo a uma "sociologia da infância" e uma "antropologia da criança". Utilizando categorias diferentes das convencionais, trabalhadas na escola, temos vivido inúmeras descobertas sobre a condição infantil, suas necessidades e desejos, as características específicas do ser criança pequena, investigadas em ambientes coletivos, que nos levam a repensar a educação formal da pequena infância de forma distinta da educação de alunos. 
Políticas de regulação, pesquisa e pedagogia na educação infantil...

E, quiçá, as pesquisas com alunos e alunas do ensino fundamental poderão também estudá-los como crianças no coletivo infantil.

Também nos preocupam as especificidades de cada momento da vida das crianças de 0 a 6 anos, e o lócus de sua educação coletiva: os móveis, brinquedos, objetos próprios para quem ainda não anda, por exemplo, literatura infantil sem letras, música, teatro, dança, performance, instalações etc. Neste sentido, as principais referências são as pesquisas recentes que estão trazendo o repertório da arte como manifestação cultural humana - não como conteúdo programático (por exemplo, os parangolés do nosso Oiticica e as concepções de infância do modernismo estudadas por Gobbi, 2004). Se o lugar de criança na sociedade do trabalho é na creche, na pré-escola e na escola, então as referências históricas para uma "pedagogia da infância" são os antigos pensadores que, mesmo sem falar em idade, falavam da educação das crianças na esfera pública. Muitos deles tratavam em seus estudos das crianças em idade pré-escolar, como: Pestalozzi, Froebel, Dewey, Montessori, Bruner, as irmãs Agazzi. O próprio Piaget, segundo o saudoso Malaguzzi da Reggio Emilia (1999), não teria construído o conceito de "egocentrismo" se tivesse vivido um pouco mais e visto as crianças convivendo nas creches. A construção do sentido de pertencimento, a gestão da ambivalência na infância (Ugazio, 1990), por exemplo, são categorias de análise que se impõem hoje e que não eram conhecidas anteriormente.

Pesquisa e universidade indissociáveis são a base de toda essa transformação nos conceitos de infância e criança. E nestes últimos tempos o curso de pedagogia passa por um momento em que retoma sua eterna crise de identidade: pedagogia/ciência da educação; pedagogia/pedagogias; ciência da educação/ciências da educação. Ao passo que algumas instâncias vêem o curso de pedagogia como a formação do intelectual da educação e de professores/as de creche, pré-escola e séries iniciais do ensino fundamental, outras consideram desnecessário esse curso de nível universitário, prevendo para esse profissional uma formação realizada apenas pelo normal superior.

Temos aí um quadro em que, além da situação crítica em que se encontra a universidade pública também neste atual governo, o curso de pedagogia, com a mais recente decisão do CNE, está desaparecendo. A recente organização curricular de alguns cursos para a formação universitária de professores/as de crianças de 0 a 10 anos corre o risco de torná-los cursos natimortos. Com a extinção do curso de magistério de nível mé- 
dio, a formação das professoras de educação infantil vive um momento, no mínimo, esquizofrênico. Com o desafio da educação de massa num país como o nosso, garantindo quantidade com qualidade, o atual governo federal, ao retomar a produção da revista Criança, ${ }^{6}$ criar o "Pro-infantil" e e a Rede de formação continuada de professores da educação básica, em parceria com universidades, demonstra interesse em manter articulada a pesquisa, a docência e a extensão. No entanto, isso ocorre num momento complicado, em que a reforma universitária proposta pelo próprio governo, e ainda em debate na sociedade, prioriza a extensão como forma de captação de recursos para a universidade pública, o que indica uma forte tendência à privatização e/ou desobrigação, pelo Estado, do seu financiamento. ${ }^{8}$

\section{A trajetória da institucionalização}

As instituições de educação infantil têm origens totalmente distintas da escola obrigatória, pública, laica e gratuita para todas as crianças de 7 anos. Como se sabe, as primeiras creches nasceram para atender aos interesses da elite que pretendeu educar as crianças das camadas populares, já que suas mães trabalhavam e não eram suas educadoras. Essas instituições surgem como substitutas das relações domésticas maternas: são religiosas, filantrópicas e, em tempos de predominância higienista, surgem patologizando a pobreza e criando o cidadão de segunda classe, inserido no sistema. Portanto, nesse âmbito, criança era sinônimo de criança pobre.

Embora ainda convivamos com estes conceitos, o direito de todas as crianças pequenas, não só das pobres, de serem educadas em instituições coletivas na esfera municipal da área educacional, não significa obrigatoriamente que elas vão ser apenas ensinadas e preparadas para a primeira série, para não se acostumaemr a ficar à toa, como dizia Comenius, antecipando a escola obrigatória. Educar e cuidar são objetivos da educação infantil, assim colocados para dar ênfase na centralidade da criança e na sua especificidade em relação ao ensino escolar. $\mathrm{O}$ que não quer dizer que a creche e a pré-escola também não tenham o objetivo, como a escola, de reproduzir e coagir, e também de transformar e libertar e, como toda educação, tem sempre o objetivo de cuidar. Também não quer dizer que a educação nessas instituições não tenha conteúdo, seja espontaneísta, só porque nelas não se trabalha com conteúdos escolares e o professor 
Políticas de regulação, pesquisa e pedagogia na educação infantil...

não ministra as disciplinas escolares formais: o professor é um professor de crianças. Se concordarmos com Guattari (1987, p. 53-54) que

simplesmente trocou-se a roupa da velha crueldade da iniciação que consiste em extirpar da criança, o mais cedo possível, sua capacidade específica de expressão, e em adaptá-la o mais cedo possível aos valores, significações e comportamentos dominantes (...). O que conta na creche, insistimos nisso, não é a técnica, é o efeito da política semiótica dos adultos sobre as crianças. Em que a atitude dos adultos que trabalham na creche favorece a iniciação das crianças nos valores do sistema? Aí é que está toda a questão (...). Os sistemas capitalistas e socialistas burocráticos haviam confiado ao pessoal das escolas uma tarefa capital: a de adaptar a criança ao saber e aos valores da sociedade contemporânea (...).

Devemos nos posicionar ao pensar nessas questões, pensando que "Hoje, no seio das creches e das escolas, alguns trabalhadores estão em posição de lutar contra estes sistemas de integração e de alienação. É neste sentido que se deveria considerar uma luta micropolítica fundamental” (Idem, ibid.).

O movimento feminista articulou, juntamente com a política do sindicalismo de esquerda, a luta por creches. O exemplo da Itália é contrastante com o brasileiro: com o boom do movimento feminista no final de 1960, em 1971 é promulgada a lei sobre as creches (Ghedini, 1994) ao passo que, no Brasil, com o mesmo movimento feminista, na mesma época, só em 1988 tivemos, com a Constituição, a garantia à educação das crianças de 0 a 6 anos em creches e pré-escolas e só em 1996 sua sistematização na LDB: 25 anos depois! A comparação faz-se mais oportuna quando nos defrontamos com a nossa legislação anterior (n. $5.692 / 71$ ), que mostra o seu descompromisso, no $2^{\circ}$ parágrafo do artigo 19, ironicamente no mesmo ano da lei italiana: Os sistemas de ensino velarão para que as crianças de idade inferior a 7 anos recebam conveniente educação em escolas maternais, jardins-de-infância e instituiçôes equivalentes.

Cabe lembrar ainda os dois artigos da LDB imediatamente anterior à acima citada (n. 4.024/61), quando explicitam que se trata de educação pré-primária ministrada em escolas maternas e jardins-de-infância. No seu artigo 24, o Estado já lava as mãos: As empresas que tenham a seu serviço mães de menores de 7 anos serão estimuladas a organizar e manter, por iniciativa própria ou em cooperação com os poderes públicos, instituições de educação pré-primária. 
Produto de pesquisas e estudos feministas nacionais e internacionais, a primeira proposta brasileira para uma política pública de educação das crianças de 0 a 3 anos veio da gestão (1986-1989) do então criado Conselho Nacional dos Direitos da Mulher (CNDM) e do Conselho Estadual da Condição Feminina (CECF de São Paulo). O material produzido, Creche - urgente, ${ }^{9}$ traz a discussão feminista pelo dever do Estado e pelo direito à creche tanto para as mulheres e os pais como para as crianças, ampliando, portanto, a luta inicial apenas pelo direito da mulher trabalhadora.

Antes disso, uma pedagogia para a infância para crianças pré-escolares já começara a ser construída como já foi mencionada, mas apenas em 1978 teremos a primeira experiência brasileira da educação da criança de 0 a 6 anos sob a responsabilidade de uma Secretaria Municipal de Educação (diferente da então tradicional divisão da educação: nas creches para as crianças de 0 a 3 anos pela Secretaria da Promoção Social/ Assistência Social/Desenvolvimento Social e nas pré-escolas para as crianças de 4 a 6 anos pela Secretaria da Educação) que nasce contemplando a creche, a pré-escola e também uma complementação das séries iniciais do então primeiro grau nos Centros Polivalentes de Educação e Cultura (CEPECS), na gestão oposicionista de João Hermann Neto (1976-1981), em Piracicaba/SP (Faria \& Mello, 1995). As crianças de 0 a 6 anos permaneciam durante período integral numa edificação construída para este fim, e, como nos parques infantis, as crianças das séries iniciais freqüentavam-nos em horário alternado ao da escola estadual. Nascia aí a educação infantil mesmo antes de estar assim nomeada.

Nesses eventos temos também os primórdios de uma pedagogia da infância sendo reeditada de forma semelhante à dos parques infantis macunaímicos de 1935 que, apesar de não receberem crianças menores de 3 anos, eram espaços educacionais, embora não escolares, para a infância de 0 a 12 anos (Faria, 2002). Como Piracicaba, outras experiências municipais com uma gestão de oposição espalharam-se pelo país, atendendo às reivindicações do movimento social. Esta gestão a que me refiro foi eleita pelo voto direto, suspenso desde 1964 com o golpe militar. Nessa eleição a oposição foi derrotada, mas podemos interpretar, apesar do que se seguiu, que as creches e pré-escolas saíram vitoriosas, pois, por exemplo, dos 570 municípios paulistas da época, em 10\% deles vencera a oposição, com o compromisso social, entre outros, de construir creches. Nesse período, apenas $0,9 \%$ das crianças brasileiras de 0 a 6 anos fre- 
Políticas de regulação, pesquisa e pedagogia na educação infantil...

qüentavam creches e pré-escolas. E quando os dados são coletados, no período em que as prefeituras tomam esse tipo de iniciativa, nos anos de 1980, este valor passa para 9,0\% (Rosemberg et al., 1985)..$^{10}$

$\mathrm{O}$ esforço de criar o espaço institucional da educação infantil já surge polemizando com as propostas governamentais do tipo "mãe crecheira”, sofrendo a resistência de segmentos da área da educação, temerosos de que, sem verba própria, a educação infantil fosse utilizar recursos comprometidos para o acesso e a permanência das crianças na escola obrigatória. No entanto, a discussão sobre a educação infantil nas políticas públicas foi muito fecunda e nesse processo seu locus começaria a ser definido como sendo a Secretaria de Educação da esfera municipal.

Antes que essa responsabilidade fosse assim definida, porém, a Secretaria do Menor do Estado de São Paulo (1986-1989) vai criar o programa creche/pré-escola, que previa colocar juntas as crianças de 0 a 6 anos. Essa experiência foi também reconhecida como marco nos primórdios do que hoje chamamos de educação infantil, mas agora dentro de um conjunto ampliado de experiências inauguradas por Piracicaba e que influenciaram sobremaneira a Constituição de 1988, que vai afirmar a creche para as crianças de 0-3 e a pré-escola para as de 4-6 anos, além da creche como direito trabalhista das mães e dos pais rurais e urbanos. Neste sentido, é interessante mencionar que essa secretaria planejou a construção de suas creches em entradas dos metrôs, para que as mães deixassem lá suas crianças, antes de continuar seu trajeto para o trabalho.

Hoje, 10,6\% das crianças de 0 a 3 anos freqüentam as creches e $65,6 \%$ das crianças de 4 a 6 anos freqüentam as pré-escolas (Censo 2003-2004, IPEA) e ainda há muita fila de espera.

\section{Rupturas e avanços}

Embora as pesquisas na área que apontam para uma pedagogia da educação infantil tenham aumentado significativamente (Rocha, 1999b) nos últimos tempos - e a pesquisa engajada articule política e pedagogia com o fim de superar aos poucos os antagonismos -, ainda temos vivos os embates educação e assistência, $0-3$ versus 4-6, falta de verba própria, direito só da mãe (e não do pai), priorizados com relação aos direitos da criança. 
Ainda recentemente, vimos esse antagonismo reforçado no folheto de educação da campanha à presidência do então candidato Lula, em 2002, que propunha universalizar a pré-escola, substituindo o FUNDEF $^{11}$ pelo FUNDEB, e a creche foi proposta apenas para as mulheres que trabalham. Nada mais inconstitucional, embora fosse uma bandeira de vanguarda na época em que o candidato era presidente do Sindicato dos Metalúrgicos do ABC e também durante a unificação do movimento social em favor da volta do estado de direito no Brasil.

A Constituição brasileira de 1988 garante o direito das crianças pequenas à educação e em 1996 a LDB o sistematiza. ${ }^{12}$ A grande novidade e o grande desafio que aparece com a LDB é a junção, na primeira etapa da educação básica, das crianças de 0-3 anos com as de 4-6 anos: duas redes diferentes, duas carreiras diferentes, dois diplomas diferentes, duas secretarias diferentes, junção também dos direitos de usuários distintos: os adultos trabalhadores (mulheres e homens, rurais e urbanos) e as crianças de 0 a 6 anos.

Com a promulgação da Constituição de 1988, os municípios foram repassando a gestão das creches, das Secretarias de Promoção Social, Assistência Social, Desenvolvimento Social para a da Educação, num processo longo e difícil de integração dos dois segmentos (o que levou a cidade de São Paulo a iniciá-lo somente recentemente). A partir daí, a educação formal em creches e pré-escolas não seria mais restrita aos programas governamentais de assistência às crianças pobres, na modalidade de creches ou programas pré-escolares em forma de jardim-da-infância para as crianças de mais alto nível socioeconômico, que continuam existindo ao lado de programas não-governamentais, filantrópicos e privados.

Até então, todas as formas de educação e/ou atendimento conviveram de maneira despreocupada quanto ao caráter de educação formal. Em outras palavras, é somente com a LDB que se falará em educação infantil como primeira etapa da educação básica e esta conviverá com outras formas de educação, gerida por vias não-formais e com uma política plural, ${ }^{13}$ para podermos dizer como os italianos: a mais e não em vez de.

$\mathrm{O}$ falso antagonismo educação/assistência, embora ainda se sinta nas práticas do cotidiano das creches e pré-escolas, não é mais assim encarado: trata-se de dois direitos da mesma criança (Santana da Silva, 1999). Novas temáticas culturais colocam a diversidade dos sujeitos: crianças com AIDS, professores homens, auxiliares de desenvolvimento infan- 
Políticas de regulação, pesquisa e pedagogia na educação infantil...

til diplomando-se como professoras de desenvolvimento infantil, inclusão das crianças com necessidades especiais etc. A educação infantil, com estas teorias pós-estruturalistas "emprestadas", revela-nos a produção da diferença e a possibilidade da superação das desigualdades por meio do convívio com essas diferenças.

\section{Retrocesos e/ou descompromissos}

$\mathrm{O}$ direito à creche foi considerado pela pediatra Marisa Lobo da Costa (1979) a maior revolução dos costumes do século XX, já que tira da mãe a exclusividade da educação das crianças pequenas. Isso levará, portanto, à necessidade de criação de condições para que o Estado assuma essa tarefa e, pelo que temos visto, as rupturas ocorreram sempre nessa direçãa, mas lembramos também que essa "atenção" vem acompanhada de "controle".

Romper com uma educação infantil antecipatória e preparatória para a escola obrigatória não é fácil, apesar das permanentes tentativas. Hoje as pesquisas dão continuidade àquelas primeiras pesquisas dos anos de 1970 e são elas que subsidiam as políticas que pretendem superar o modelo escolar na educação infantil. Na prática docente, porém, ainda não é esta a pedagogia predominante, em virtude da forte presença seja da formação para o magistério tradicional na educação pré-escolar, onde há o predomínio da psicologia do desenvolvimento e do binômio ensino/aprendizagem em detrimento de outras vertentes nas pesquisas em psicologia e também em pedagogia, história, arte, antropologia, sociologia, entre outras, que investigam o que as crianças pequenas criam entre elas, o que desejam e o que necessitam. Seja em virtude também da forte presença da educação da vida doméstica e/ou da área da enfermagem no cotidiano das creches.

Em diálogo também com o Movimento Interfóruns da Educação Infantil do Brasil (мІЁB, 2001), o atual governo federal lança a proposta para que a educação obrigatória passe a ser de 9 anos, sob a responsabilidade do Estado, começando aos 6 anos de idade. Polemizado, o movimento e a Sociedade Civil mantêm-se divididos entre essa possibilidade e uma outra, em que se preserve o direito, adquirido recentemente, de a educação infantil prever a educação da criança de 0 a 6 anos, ou seja: a escola obrigatória passaria a ser de 9 anos, começando, como tem sido, com as crianças com 7 anos e terminando quando alcançassem 15 anos. 
Como se pode perceber, a preocupação com as crianças nem sempre está presente nos projetos: é o que ocorre com esta medida, que está muito mais voltada a, equivocadamente, universalizar o pré. A complexidade de uma instituição educativa de caráter não-obrigatório e tendo como usuários atores tão distintos, por razôes tão distintas e tudo isso tão diferente da escola obrigatória, exige normas de funcionamento claras e democráticas, com bases teóricas sólidas. Senão, note-se o que já vivemos há 20 anos: dados do PNAD de 1982, 85, 87 mostraram quase um milhão de crianças maiores de 7 anos freqüentando a pré-escola. A maioria delas entre 7 e 9 anos de idade, mas chegando até os 13 anos. A maioria delas negras e do Nordeste (apud Rosemberg, 1991). Vemos que antecipar a escola obrigatória não se faz impunemente; antecipa-se também a exclusão social nela embutida, como já alertara Solange Jobim e Souza em 1984.

Hoje sabemos que a criança é um ser humano competente, capaz de múltiplas relações, portador de história, produzido e produtor de cultura, e assim é sujeito de direitos. Pode-se dizer que na França, desde os anos de 1970, com esta visão sobre as crianças pequenas, freqüentar a "escola maternal" com 3 anos de idade já faz parte do senso comum (Chamboredon \& Prévot, 1986). No entanto, ainda no nosso dia-a-dia, no interior de uma sociedade adultocêntrica (Rosemberg, 1976), prevalece a ênfase na sua dependência e incompletude com relação ao adulto e também na necessidade de sua proteção, pela mãe, na esfera privada. Isso não quer dizer que, como já foi mencionado, longas filas estão à espera de vagas. ${ }^{14}$

Foi o que serviu de justificativa para o Ministério da Educação, logo no início da atual gestão, com o então ministro Cristóvam Buarque, quando propôs uma bolsa mensal de 50 reais para as mães permanecerem em casa com seus filhos pequenininhos. Praticamente natimorta, essa proposta foi suprimida pela pressão da sociedade articulada pelo MIEIB. ${ }^{15}$

Cumprindo os compromissos do governo com o MIEIB, foi criado o Conselho de Políticas para a Educação Básica (CONPEB) no segundo semestre de 2003, que englobou os então recém-criados Conselhos de Educação Infantil, de Ensino Fundamental, de Ensino Médio e de Educação de Jovens e Adultos. ${ }^{16}$

Deu-se início então à elaboração dos documentos nacionais da política para primeira etapa da educação básica. O CONPEB responsabilizou- 
Políticas de regulação, pesquisa e pedagogia na educação infantil...

se pela "Política Nacional de Educação Infantil: pelo direito das crianças de zero a seis anos à Educação" (2005). Foi encomendado para Maria M. Campos e Maria Lúcia Machado, da FCC, o documento "Parâmetros de qualidade para a educação infantil” (2005) e para o grupo de pesquisa Ambiente Educação, da UFRJ, os "Padrões de infra-estrutura para as instituiçōes de educação infantil”. Em dois momentos, entre 2004 e 2005, oito seminários foram organizados pelo Departamento de Educação Infantil, coordenado por Karina Rizek Lopes, e discutidos esses documentos preliminares que definiriam a política nacional de educação infantil no atual governo. O primeiro deles já se encontra distribuído; os outros ainda estão em fase de discussão e acabamento. ${ }^{17}$ Embora tenha havido muita discussão, os documentos inacabados ainda são acanhados com relação ao avanço da pesquisa na área. Os documentos foram elaborados na certeza de que a creche seria contemplada pelo FUNDEB, mas até o momento vive-se o impasse posto pela possibilidade de retrocesso com a fragmentação no interior da educação infantil e, portanto, no interior da educação básica.

Em junho deste ano de 2005, foi encaminhado para a Câmara, e aprovado nesta instância, o FUNDEB sem incluir as crianças de 0 a 3 anos. O movimento da sociedade articulado pelo MIEIB insiste, no momento, na luta para reverter esta situação com bastante esperança, dado o sucesso da manifestação dos "fraldas pintadas" do dia 31 de agosto último.

Da possibilidade de exclusão das crianças de 0-3 anos no FUNDEB à possibilidade de extinção dos cursos de pedagogia e privatização da universidade pública, a educação infantil está de fato correndo sérios riscos e as crianças de 0 a 6 anos, que recentemente adquiriram o direito de ser educadas em creches e pré-escolas, vivem um momento instável de possível perda de direitos: as de 6 anos perdem a pré-escola e vão para a $1^{\text {a }}$ série, as de 0 a 3 anos dependerão de o município ter ou não ter verba para creches, pois poderão estar fora do FUNDEB. Ademais, se a educação infantil se reduzir à educação das crianças de 4 e 5 anos, corre o risco de, nos moldes de hoje, ser antecipatória, comportando-se apenas como classe de alfabetização e/ou preparatória, comportando-se como pré-alfabetização mesmo o Plano Nacional de Educação tendo as extinguido.

Ainda hoje estamos sem uma política de financiamento para o setor, o que impede o cumprimento da Constituição, pois os artigos como lá aparecem não são auto-aplicáveis. Necessitam não somente da sistematização de conteúdo, como propõe a LDB de 1996, como também da de- 
finição de fontes de recurso e criação de verba própria para seu cumprimento. A situação é complexa e original, pois se trata de um direito à educação de crianças e, também, concomitante de um direito dos adultos trabalhadores, pais e mães de crianças de 0 a 6 anos. Totalmente diferentes daqueles direitos explicitados na CLT de 1943, esses são considerados a primeira etapa da educação básica, não-obrigatórios para as famílias, mas obrigatórios para o Estado na esfera municipal e, portanto, uma opção da família e complementar à sua educação.

As ditas políticas neoliberais, já chamadas de minimalistas com relação à educação, mostram-se ainda "menores" para a educação das crianças de 0 a 6 anos e muitas vezes não têm sequer a criança como alvo, sequer se pronunciam a respeito da primeira etapa da educação básica.

São dois prá lá três prá cá ${ }^{18}$

Como nos ensinam os exemplos de outros países, seria recomendável uma política plural para essa etapa da educação básica, que dê conta dos tantos tipos de família e de arranjos familiares, numa sociedade em movimento, com profissionais diplomados e atualizados. Desses exemplos poderíamos citar as experiências dos tipos "mães crecheiras", "creches domiciliares", que existem inclusive na Suécia, atendendo a um dos tipos de demanda das famílias, assim como o programa cubano "Educa tu hijo", "Tempo per le famiglie", de Milão, e "Maison verte", na França.

No caso do Brasil, caberia uma política plural integrada com outras secretarias, outros ministérios, mas se não exigimos profissionais diplomados e atualizados para esse tipo de programas, não se enquadrarão nas exigências do Ministério e das Secretarias de Educação como primeira etapa da educação básica. A parceria com os órgãos públicos de cultura podem ser fecundas, como foram em 1935 os parques infantis paulistanos criados pelo poeta Mario de Andrade.

Vale a pena, a título de conclusão, um esclarecimento: sabemos que na Escandinávia e mesmo na Europa mediterrânea, na Itália tantas vezes aqui citada, quase não nascem crianças e, no Brasil, um exemplo poderia ser fatal para qualquer cópia ou mesmo comparação: na cidade de São Paulo nascem 400 crianças por dia... Trata-se, portanto, de propor educação de massa e elaborar um plano de Estado e não apenas um 
Políticas de regulação, pesquisa e pedagogia na educação infantil...

plano deste governo. Interromper urgentemente práticas maquiadoras de estatísticas e ofuscadoras de uma política de Estado, tais como: a) transferir as crianças de 6 anos para o ensino fundamental - e, infelizmente, ainda por cima, não ter sequer a certeza de alcançar os 9 anos sob a responsabilidade do Estado, como prometido; b) as classes de alfabetização para as crianças de 6 anos pré-classificadas como incapazes; c) o Poder Judiciário determinando colocar a criança na creche, desrespeitando os critérios da fila de espera e considerando a instituição uma substituta materna e não um direito à educação - a determinação coloca-se assim como puniçãao às mães, entendidas como impossibilitadas e desnaturadas (sic); e d) pena assistida para jovens infratores de trabalharem em creches, pois não são diplomados para exercer tal cargo.

Podemos constatar uma desarticulada pluralidade de subsistemas dentro do sistema de ensino e, desse modo, uma outra forma de o Estado controlar a educação infantil: uma CLT de 1943, ainda em vigor sem regulamentar devidamente as empresas privadas com relação aos direitos trabalhistas das mulheres e o direito de amamentar em berçário, dentro do local de trabalho; jurisprudência com relação aos dissídios sindicais, que reconhecem a creche como direito do pai e da mãe que trabalham; educação pelas vias não-formais pulverizada em ONGs, entidades filantrópicas, privadas e confessionais sem regulamentação, por bem ou por mal; lei orgânica dos municípios reconhecendo as pré-escolas públicas - e privadas, em alguns municípios -, ajustadas às Secretarias de Educação; creches privadas comportando-se como serviços e creches públicas compondo a primeira etapa da educação básica, com as pré-escolas participando da lei orgânica; os planos municipais de educação.

Como vimos, desde a Lei 4.024/61 o Estado brasileiro desobrigava-se de garantir os direitos aqui explicitados, propondo parceria com o setor privado para a educação anterior à escola obrigatória. As pesquisas ${ }^{19}$ têm mostrado o alto grau de inovação, transparência e rigor em muitos municípios que tentam articular a política, a pesquisa e a pedagogia. $\mathrm{O}$ documento "Subsídios para credenciamento e funcionamento de instituições de educação infantil"20 (MEC, 1998) poderá, com os devidos ajustes, ser muito útil na orientação das políticas de regulação para a educação infantil, pendendo para garantir, fora do papel, o direito conquistado, no papel, em 1988.

$\mathrm{O}$ tom militante deste texto corresponde às vozes (e aos gritos) das "criancistas-criançólogas" que reconhecem as dificuldades de uma políti- 
ca integrada para a infância, mesmo estando de posse das pesquisas que mostram o protagonismo deste "cidadão de pouca idade" (como diz W. Benjamin), criando culturas infantis, construindo as várias dimensões humanas e o sentido de pertencimento.

No presente momento, queremos garantir a verba para a educação dos pequenininhos de 0-3 anos, no FUNDEB, que será pela primeira vez discutido pelo Legislativo, e uma universidade pública de qualidade que forme os pedagogos para a educação infantil. Como fazer um mapa durante um terremoto, é impossível escrever este artigo neste momento sem externar a esperança da realização de nossas bandeiras, em defesa dos direitos das crianças em geral e das pequenas em particular, já que, estando elas nesta fase da vida, não dispõem dos instrumentos necessários para se impor e exigir o cumprimento dos seus direitos. Sem verba própria, ou com os míseros 17 reais per capita, então fornecidos pelo Ministério da Previdência, não será possível alcançar este sonho, superar o falso dilema qualidade versus quantidade, garantindo quantidade com qualidade. E esta se alcança com profissionais da educação diplomados e atualizados, capazes de uma programação curricular que não vise à homogeneização da criançada.

Temos de combater os programas episódicos, que pulverizam os recursos e não estão voltados para uma política articulada, enraizada na diversidade cultural brasileira. Em seminário sobre financiamento na educação infantil no que tange às recomendaçôes, foram apontadas:

- "a exigência de aprofundamento das discussões sobre financiamento da educação infantil, privilegiando as diferentes propostas de estratégias de financiamento da educação com o necessário detalhamento técnico-financeiro;

- a urgência de atuação da União, por meio do Ministério da Educação, no estabelecimento de parâmetros de qualidade da educação infantil;

- a necessidade de definição do custo-aluno-qualidade da educação infantil;

- a importância de múltiplos esforços na realização de estudos e pesquisas de custo e de demanda para qualificar melhor as propostas de custos, de qualidade e de expansão do atendimento;

- a possibilidade de organização de uma publicação que, a partir do Seminário, contribua para potencializar e ampliar as discus- 
Políticas de regulação, pesquisa e pedagogia na educação infantil...

sões sobre Financiamento da Educação Infantil". (Coelho \& Barreto, 2004, p. 15)

Como se vê, estas recomendações vão na contramão das políticas de ação afirmativa tão na moda, isto é, da filantropia neoliberal do século XXI. Que também precisa ser combatida, em benefício dos direitos das crianças pequenas a uma pedagogia da diferença, para a superação das desigualdades. Este é o papel fundamental do MIEIB neste momento: negociar com este governo e garantir a definição de uma política de Estado para a primeira etapa da educação básica. Cuidar para que não se invada a privacidade infantil e para que a ética nas pesquisas com as crianças pequenas seja sempre cada vez mais observada. Que o binômio atenção/controle penda cada vez mais para a atenção.

A luta pela polivocidade da expressão semiótica da criança nos parece então ser um objetivo essencial dessa micropolítica ao nível da creche. Recusar fazer "cristalizar" a criança muito cedo em indivíduo tipificado, em modelo personológico estereotipado (...). Não se trata aqui de opor uma formação a outra, uma codificação a outra, mas de criar condições que permitam que indivíduos adquiram meios de expressão relativamente autônomos e portanto relativamente não-recuperáveis pelas tecnologias das diversas formaçōes de poder (estatais, burocráticas, culturais, sindicais, da comunicação de massa etc...). Se, ao atingir a idade adulta, num momento ou noutro ele decide assumir as roupas e papéis que o sistema lhe apresenta, convém que ele possa fazê-lo sem que lhe colem à pele a ponto de não mais poder desfazer-se deles e então passar a investir nos próprios valores repressivos de que estas roupas e papéis são portadores. (Guattari, 1987, p. 54-55)

Com estudos, pesquisas e o melhor conhecimento das crianças desde seu nascimento, os adultos profissionais que com elas atuam estarão aptos a estabelecer condições para que as roupas não colem à pele e saberão, cada vez mais, dos desejos e das necessidades infantis e que muitas crianças, como disse Alice: não querem ser contratadas e não gostam de geléia.

Recebido e aprovado em setembro de 2005.

\section{Notas}

1. $\mathrm{Na}$ V CBE de 1988, a professora Clotilde torna pública essa mudança de paradigma nas pesquisas do seu grupo, voltado agora também para a política nacional de educação da criança de 0 a 6 anos, tornando possível fazer da psicologia uma das ciências construtoras 
da pedagogia para esta fase da vida e superar a postura predominante na época, que entendia a pedagogia como psicologia aplicada.

2. Esse documento faz parte dos "cadernos das carinhas", assim chamados porque as capas eram iguais, variando apenas a cor, com desenhos de rostinhos de crianças negras, brancas, mulatas, japonesas, indígenas etc.

3. Diferente da França, a Itália não tem uma política nacional articulada, mas sim experiências exemplares em todo o norte do país. Em 1968 caiu um governo italiano para as préescolas tornarem-se públicas, gratuitas e laicas, como são as escolas elementares obrigatórias desde 1911. No entanto, as creches (com grande descontentamento e com luta permanente para sua transformação) são serviços de demanda individual, subsidiadas pelas prefeituras, pagas proporcionalmente à renda da família (Faria, 1994).

4. Becchi (1983) denomina a pesquisa sobre as mulheres, por exemplo, de pesquisa interpretativa.

5. Como, por exemplo, a revista Educação \& Sociedade, Cadernos de Pesquisa, Educação \& Realidade, Pro-Posiçôes, Perspectiva, Revista da ANPUH, entre outras.

6. Desde os anos de 1980 voltada para a formação continuada das "professoras leigas" da préescola. Passa agora a ser para todas as profissionais da educação infantil.

7. Ensino médio na modalidade magistério a distância para a formação das "professoras leigas" da educação infantil.

8. Neste exato momento em que finalizo este texto, a Assembléia Legislativa do estado de São Paulo ainda vai votar o veto do governador para o aumento do repasse do ICMS para as universidades públicas paulistas e o Instituto Paula Souza.

9. "Creche - urgente": n. 1 "Criança, compromisso social”, n. 2 "Organização e funcionamento", n. 3 "Espaço físico", n. 4 "O dia-a-dia” (não foram publicados os outros números 5 e 6) e n. 7 "Relatos de experiência". Estes cinco caderninhos em preto e branco, variando de 30 a 40 páginas, foram ilustrados pelo engenhoso Marcelo Paiva e por Virginia Fujiwara e produzidos por uma equipe de profissionais que já estudavam e atuavam em creches.

10. Ainda no estado de São Paulo, na primeira campanha eleitoral que retoma as eleiçóes para governador, durante as reunióes e discussões que previam as futuras secretarias de estado para um governo de oposição contra a ditadura, Maria Malta Campos cria o grupo da educação das crianças de 0 a 6 anos que produz um documento que indica a educação formal em creches e pré-escolas, articulada no entanto com outras futuras secretarias - lazer, assistência, saúde, justiça, educação, cultura, trabalho. O grupo de mulheres que comporá o Conselho Estadual da Condição Feminina (CECF) também participa dessas discussões.

11. Vale lembrar os grandes debates e as publicaçôes criticando o FUNDEF e a transferência para o ensino fundamental de verbas locadas na educação infantil municipal. Pergunta-se: política de regulação e/ou política de exclusão?

12. Embora até hoje não se possa exigir seu cumprimento, pois ainda não está definida a sua verba própria.

13. Ainda hoje, sem nossas definições nacionais para funcionamento e credenciamento das creches e pré-escolas públicas e formais, o setor privado, filantrópico, comunitário e as ONGs podem cadastrá-las na Secretaria Municipal de Finanças e recolher o ISS, comportando-se como um serviço.

14. Em 1992 (Musatti) é publicada na Itália uma pesquisa mostrando que, entre $90 \%$ das famílias que matriculam seus filhos e filhas na pré-escola, apenas $30 \%$ delas gostariam de matriculá-los na creche. Mesmo assim, não há vagas para toda a demanda.

Educ. Soc., Campinas, vol. 26, n. 92, p. 1013-1038, Especial - Out. 2005

Disponível em <http://www.cedes.unicamp.br> 
Políticas de regulação, pesquisa e pedagogia na educação infantil...

15. Durante a campanha eleitoral, ainda com os cinco candidatos na disputa, o MIEIB solicitou adesão para se estabelecer sua interlocução com o Ministério da Educação durante o novo governo, a fim de garantir o cumprimento da LDB, isto é, que a educação infantil continuasse considerada a primeira etapa da educação básica. Somente o candidato Lula se manifestou e assinou o documento de adesão. Ainda na gestão de Cristóvam Buarque no Ministério da Educação, o MIEIB foi recebido para levar suas reivindicações e saiu satisfeito com uma delas atendida: a Secretaria de Ensino Fundamental passa a ser Secretaria de Educação Infantil e Ensino Fundamental.

16. O CONPEB é composto por representantes da sociedade civil: ANPED, MIEIB, CONSED, ANFOPE, CNTE, UNDIME, FORUMDIR, MIEIB, CONTEC, UNCME, CNE e também pela UNESCO e pelo UNICEF.

17. Antes que o atual governo fizesse sua proposta, assumindo seu papel no cumprimento de direitos, na gestão anterior foi elaborado o "Referencial nacional curricular para a educação infantil" (ver Cerisara, 2002 e 2005) e no governo precedente foi elaborada a primeira "Política nacional de educação infantil", em 1994. Antes, portanto, de a educação infantil ser considerada primeira etapa da educação básica, como será a partir da LDB de 1996, mas já se referindo à educação das crianças de 0 a Ganos. Essa produção dá início aos já mencionados "cadernos das carinhas". Como também já referido, em 1987 tivemos a primeira proposta que apontava uma política pública para creches, feita pelas feministas. Em 1989, o UNICEF e o governo federal, por intermédio do IPEA, solicitaram à FCC uma pesquisa sobre os programas para crianças de 0 a 6 anos sob responsabilidade federal. Os dados foram colhidos nos Ministérios da Saúde, Trabalho, Educação, Interior, Justiça e no BNDEs. Os resultados foram colocados à disposição no relatório "Aspectos socioeducativos e sugestôes para uma política nacional de educação da criança de 0 a 6 anos no Brasil”, e sua versão resumida foi publicada em forma de livro: Creches e pré-escolas no Brasil (Campos et al., 1992). No contexto deste projeto, e com o apoio da ANPED, é realizado o primeiro seminário sobre "Financiamento de políticas públicas para as crianças de 0 a 6 anos" (Campos \& Faria, 1989) e, em 2003, a Comissão de Educação, Cultura e Desporto da Câmara dos Deputados, o Ministério da Educação e a UNESCO realizaram o seminário "Financiamento para a educação infantil - perspectivas em debate” (Coelho \& Barreto, 2004).

18. Parafraseando o título do artigo de Rosemberg (2003), "Sísifo e a educação infantil brasileira".

19. O bienal Congresso Paulista de Educação Infantil (COPEDI), organizado pelo Fórum Paulista de Educação Infantil, membro do MIEIB, tem sido a grande contribuição deste novo ator do movimento social. Tem divulgado as pesquisas, as políticas e as práticas pedagógicas brasileiras e também internacionais.

20. Esse documento, produto de seminário realizado no final da gestão de Angela Barreto no COEDI-MEC, deveria ser o último documento "das carinhas", o de cor vermelha. No entanto, ele foi impresso com outra capa e foi pouquíssimo divulgado pela sua sucessora.

\title{
Referências bibliográficas
}

\author{
ABRAMOWICZ, A. O direito das crianças à educação infantil. Pro-Posi- \\ çôes, Campinas, v. 14, n. 3 (42), p. 13-24, 2003.
}

BECCHI, E. Molte infanzia, poche storie. Ricerche pedagogiche, Parma, n. 68-9, p. 1-15, 1983. 
BERTONI JOVINE, D. L'educazione infantile in Italia. Scuola e cittá, Roma, n. 2-3, 1965.

BONOMI, A. O relacionamento entre educadores e pais In: Bondioli, A.; Mantovani, S. (Org.). Manual de educação infantil de 0 a 3 anos. Porto Alegre: Artes Médicas, 1995. p. 161-172.

BRASIL. Ministério da Educação. Secretaria de Educação Básica. Subsidios para credenciamento e funcionamento de instituiçôes de educação infantil. Brasília, DF: MEC,1998. v.1-2.

BRASIL. Ministerio da Educação. Secretaria de Educação Básica. Padrões de infra-estrutura para as instituiçôes de educação infantil e parâmetros de qualidade para a educação infantil. Documento preliminar. Brasília, DF, 2004.

BRASIL. Ministerio da Educação. Secretaria de Educação Básica. Politica Nacional de Educação Infantil: pelo direito das crianças de zero a seis anos à educação. Brasília, DF: MEC, 2005.

CAMPOS, M.M.; FARIA, A.L.G. (Org.). Financiamento de políticas públicas para crianças de 0 a 6 anos. Cadernos ANPED, Belo Horizonte, n. 1, p. 43-56, 1989.

CAMPOS, M.M.; ROSEMBERG, F.; FERREIRA, I.M. Creches e préescolas no Brasil. São Paulo: Cortez, 1992.

CARVALHAL, T.F. Saramago na universidade. Porto Alegre: UfRGS, 1997.

CARVALHO, A.M.; BERALDO, K. Interação criança-criança: ressurgimento de uma área de pesquisa e suas perspectivas. Cadernos de Pesquisa, São Paulo, n. 71, p. 55-61, 1989.

CERISARA, A.B. Referencial curricular nacional para a educação infantil no contexto das reformas. Educação \& Sociedade, Campinas, v. 23, n. 80, p. 329-348, 2002.

CERISARA, A.B. A produção acadêmica na área da educação infantil a partir da análise de pareceres sobre o RCNEI: primeiras aproximaçôes. In: Faria, A.L.G.; Palhares, M. (Org.). Educação infantil pós-LDB: rumos e desafios. 5. ed. Campinas: Autores Associados, 2005. p. 19-49.

CHAMBOREDON, J.; PRÉVOT, J. O "ofício de criança”: definição so- 
Políticas de regulação, pesquisa e pedagogia na educação infantil...

cial da primeira infância e funções diferenciadas da escola maternal. Cadernos de Pesquisa, São Paulo, n. 59, p. 32-56, 1986.

COELHO, R.C.; BARRETO, A.R. (Org.). Financiamento da educação infantil. Brasília, DF: UNESCO, 2004.

COSTA, M.L. A criança como objeto da medicina. Cadernos de Pesquisa, São Paulo, n. 31, p. 10-16, 1979.

FARIA, A.L.G. Impressões sobre as creches no norte da Itália In: Rosemberg, F.; Campos, M.M. (Org.). Creches e pré-escolas no Hemisfério Norte. São Paulo: Cortez, 1994. p. 211-232.

FARIA, A.L.G. A contribuição dos parques infantis de Mario de Andrade para a construção de uma pedagogia da educação infantil. Educação \& Sociedade, Campinas, v.20, n. 69, p. 60-91, 1999.

FARIA, A.L.G. Educação pré-escolar e cultura. 2. ed. São Paulo: Cortez; Campinas: UNICAMP, 2002.

FARIA, A.L.G.; MELLO, S.A. Educação infantil e política no Brasil: relato de uma experiência. Cadernos da FFC (Unesp), Marília, v. 4, n. 2, p. 133-146, 1995.

FERNANDES, F. Folclore e mudança social na cidade de São Paulo. 2. ed. Rio de Janeiro: Vozes, 1979.

GHEDINI, P.O. Entre a experiência e os novos projetos: a situação da creche na Itália. In: Rosemberg, F.; CAmpos, M.M. (Org.). Creches e préescolas no Hemisfério Norte. São Paulo: Cortez, 1994. p. 189-209.

CAMPOS, M.M.; MACHADO, M.L. Parâmetros de qualidade para a educação infantil. Brasília, 2005. (versão em andamento)

GOBBI, M.A. Desenhos de outrora, desenhos de agora: os desenhos das crianças bem pequenas dos parques infantis de Mario de Andrade. 2004. Tese (Doutorado) - Faculdade de Educação, Universidade Estadual de Campinas, Campinas.

GUATTARI, F. As creches e a iniciação. In: GuATtari, F. Revolução molecular: pulsação política do desejo. 3. ed. São Paulo: Brasiliense, 1987.

JOBIM E SOUZA, S. Pré-escola: em busca de suas funções. Cadernos de Pesquisa, São Paulo, n. 48, p.74-76, 1984. 
KISHIMOTO, T.M. A pré-escola em São Paulo (1877 a 1940). São Paulo: Loyola, 1988.

KISHIMOTO, T.M. O jogo, a criança e a educação. 1992. Tese (LivreDocência) - Universidade de São Paulo, São Paulo.

KRAMER, S. A política do pré-escolar no Brasil: a arte do disfarce. Rio de Janeiro: Achiamé, 1982.

KULHMANN JUNIOR, M. Instituições pré-escolares assistencialistas no Brasil (1899-1922). Cadernos de Pesquisa, São Paulo, n. 78, p. 17 26, 1991.

LA GUARDIA, L.S.; LUCCHINI, E. Asili nido in Italia: il bambino de 0-3 anni. Milano: Marzorati, 1980.

MALAGUZZI, L. História, idéias e filosofia básica. In: EDwArds, C.; Gandini, L.; Forman, G. (Org.). As cem linguagens da criança: a abordagem da Reggio Emilia na educação da primeira infância. Porto Alegre: Artes Médicas, 1999. p. 59-104.

MANTOVANI, S.; GAY, R.. Uma profissão a ser inventada: o educador da primeira infância. Pro-posiçôes, Campinas, v. 10, n. 1 (28), p. 75-98, 1999.

MARCEllinO, N. Pedagogia da animação. Campinas: Papirus, 1990.

MOVIMENTO INTEFORUNS DE EDUCAÇÃO INFANTIL DO BRASIL (MIEIB). Escritos preliminares. 2001.

MUSATTI, T. (Org.). La giornata del bambino. Bolonha: Il Mulino, 1992.

ROCHA, E.A.C. A pesquisa em educação infantil no Brasil: trajetória recente e perspectivas de consolidação de uma pedagogia. Florianópolis: UFSC, CED, Núcleo de publicações, 1999a.

ROCHA, E.A.C. As pesquisas sobre educação infantil no Brasil: a trajetória da ANPED (1990-1996). Pro-Posiçôes, Campinas, v. 10, n. 1 (28), p. 54-74, 1999 b.

ROSEMBERG, F. Educação para quem? Ciência \& Cultura, São Paulo, v. 28, n. 12 , p. $1466-1471,1976$. 
Políticas de regulação, pesquisa e pedagogia na educação infantil...

ROSEMBERG, F. Raça e educação inicial. Cadernos de Pesquisa, São Paulo, n. 77, p. 25-34, 1991.

ROSEMBERG, F. Sísifo e a educação infantil brasileira. Pro-Posições, Campinas, n. 40, p. 177-198, 2003.

ROSEMBERG, F.; CAMPOS, M.M.; PINTO, R.P. Creches e pré-escolas. São Paulo: Nobel; CECF, 1985.

ROSSETTI-FERREIRA, M.C. A pesquisa na universidade e a educação da criança pequena. Cadernos de Pesquisa, São Paulo, n. 67, p. 79-89, 1988.

SILVA, A.S. Educação e assistência: direitos de uma mesma criança. ProPosiçôes, Campinas, v. 10, n. 1 (28), p. 40-53, 1999.

UGAZIO, V. (Org). Manuale di psicologia educativa: prima infanzia. Milão: Franco Angeli, 1990. 